\title{
Analysis of the Spatial Structure of Regional Enterprises and Its Impact on Regional Economic Development Based on the Data Envelopment Analysis Model (DEA)
}

\author{
Lei Wang, ${ }^{1}$ Yuan $\mathrm{He}^{2}$ and Tongwen Wang ${ }^{3}{ }^{3}$ \\ ${ }^{1}$ School of Economics and Management, Jiaozuo Normal College, Jiaozuo 454000, China \\ ${ }^{2}$ Department of Finance and Business, Henan College of Industry \& Information Technology, Jiaozuo 454000, China \\ ${ }^{3}$ School of Architectural and Artistic Design, Henan Polytechnic University, Jiaozuo 454000, China
}

Correspondence should be addressed to Tongwen Wang; wangtw@jzsz.edu.cn

Received 12 November 2021; Revised 9 December 2021; Accepted 11 December 2021; Published 26 December 2021

Academic Editor: Miaochao Chen

Copyright (c) 2021 Lei Wang et al. This is an open access article distributed under the Creative Commons Attribution License, which permits unrestricted use, distribution, and reproduction in any medium, provided the original work is properly cited.

This paper adopts the data envelopment analysis (DEA) model to conduct an in-depth study and analysis of the spatial structure of regional enterprises and their impact on regional economic development and to apply the analysis of the impact between the two. Firstly, the concepts of urban agglomeration, regional spatial pattern evolution, and coordinated regional development and their connotations are explained to define the research topic of this paper. Then, we systematically analyze the theory of regional economic growth, development stage theory, spatial polarization theory, and regional spatial association theory and review the existing studies on regional economic growth, regional development stage, regional spatial association, and pattern evolution, as well as the efficiency and quality of regional economic growth, which further clarify the research focus and research ideas of this paper. The time evolution, spatial divergence, and spatial association characteristics of the economic growth rate of the central urban agglomerations are measured, then the DEA model and entropy value method are used to calculate the economic growth efficiency and economic growth quality of the urban agglomerations, respectively, the time evolution characteristics and spatial pattern evolution characteristics of the economic growth efficiency and economic growth quality are analyzed, and finally, the coupled model of regional economic growth rate, efficiency, and quality is constructed. Finally, a coordination model of the coupling of regional economic growth rate, efficiency, and quality is constructed and the time-series evolution characteristics and spatial-temporal divergence characteristics of the coupling coordination degree of the three are comprehensively analyzed, and the spatial classification of the coupling coordination type of each county unit is made. The direction and path of regulation for the optimization of spatial structure and coordinated spatial development of urban agglomerations are proposed, and finally, the leading factors for the reorganization of the regional economic spatial structure are analyzed, and the regulatory countermeasures for the optimization of the economic spatial structure of urban agglomerations are proposed according to the spatial structure of urban agglomerations and their evolutionary characteristics.

\section{Introduction}

In the process of industrialization, an important supporting force for the economic development of a region is the development of industrial enterprises, especially industrial enterprises above the scale. The total output value of enterprises above the scale can account for more than $90 \%$ of the total industrial output, which plays an important role in helping regional economic development, promoting tax revenue and employment, optimizing industrial structure, and promoting technological progress [1]. At the same time, the spatial distribution of industrial enterprises in a region also has a profound impact on the establishment and evolution of the spatial pattern of the town system. Therefore, an in-depth study of the development and evolution of the spatial structure of industrial enterprises in Shaanxi Province and the improvement process of their total factor productivity is important to enhance the rationality of the location choice of industrial enterprises and to promote the benefits of industrial agglomeration. At the same time, 
the industrial transfer may also occur in certain special industries with the color of planned economy, mainly from the perspective of strategic development [2]. In the process of industrialization, an important supporting force for the economic development of a region is the development of industrial enterprises, especially the development of industrial enterprises above designated size. The total output value of enterprises above designated size can account for more than $90 \%$ of the total industrial output, which plays an important role in boosting regional economic development, promoting taxation and employment, optimizing industrial structure, and promoting technological progress. At present, the international industrial division of labor is further adjusted, and the industries in the eastern coastal areas that can be observed are gradually shifting to the central and western regions. In the context of the belt and road construction, the central and western regions have been able to overcome their shortcomings of low openness to the outside world and high transportation costs and actively undertake the transfer of domestic and foreign industries, so that the spatial pattern of industries and the industrial division of labor nationwide can be optimized and upgraded. The choice of spatial development strategy is also a process of continuous innovation. In this paper, starting from the evolution of the spatial pattern of industrial enterprises, through the analysis and generalization of the location choices of enterprises in different industries and different tenures, we propose strategies for the spatial development of industrial enterprises with local characteristics according to the actual situation in Shaanxi [3]. If the methods of classical econometrics are directly applied to the analysis and processing of spatial data, the spatial dependence of these data is usually not obtained, and the evolutionary characteristics and laws of economic phenomena cannot be fully revealed. Therefore, when analyzing and processing spatial data, it is necessary to adopt appropriate spatial statistical analysis methods.

The research on the efficiency of the regional tourism industry is more complicated, but the key issues in the process of regional tourism industry efficiency evolution are not grasped enough. The evolution of the regional tourism industry is a dynamic development process from disorder to order and gradually approaching the equilibrium state, which is open and dissipative. To accurately grasp and clarify its spatial-temporal evolution process and a driving mechanism is the core problem to be solved in the study of regional tourism industry efficiency. This paper attempts to explore the human geography connotation based on the scale, namely, evaluating the efficiency of the regional tourism industry by the ontological reality scale, exploring its spatial-temporal evolution process, and driving mechanism by the epistemological analysis scale, and providing countermeasures for its reform and development by the practical scale of subjective application [4]. An attempt is made to study in-depth the spatial-temporal evolution process and driving mechanism of regional tourism industry efficiency from various aspects such as attribute scale, spatial-temporal scale, methodological scale, and practical scale. Therefore, to a certain extent, this paper helps to enrich the research content of regional tourism industry efficiency and improve the research framework of tourism efficiency. On the other hand, the introduction of evolutionary economic geography theory is a useful attempt and exploration of regional tourism industry efficiency evolution research with a new research perspective, and at the same time, it can combine evolutionary economic geography theory with the local practice of tourism development in China, enrich the application of the theory in regional tourism industry efficiency evolution research, and provide support for the formation of localized tourism research combining external theory and internal practice. Scientific spatial layout is an important guarantee for regional economic growth and product development, and coordinated development of the national territory under the idea of the main functional area is the current dominant regional spatial development concept [5]. On the one hand, the existence of regional economic differences is the basis of regional division of labor and regional competition. Appropriate regional differences are conducive to the formation of regional economic development momentum and competitiveness, promote the flow and optimal allocation of regional production factors, and promote competition between regions; on the other hand, excessive regional economic differences will aggravate local market segmentation, and regional differences that exist for a long time or are too large will encourage the prevalence of local protectionism, hinder regional division of labor and cooperation, and weaken the economic development capacity of underdeveloped regions, thereby affecting the overall region. Sustainable economic development: The division of the main functional area is mainly constrained by the regional natural ecological environment, location, and economic development basis, economic carrying capacity, and other factors. According to the national main functional area plan, the national land is divided into optimally developed areas, key developed areas, restricted developed areas, and prohibited developed areas according to the development mode. The introduction of the main functional area plan is an important refinement and adjustment of the regional economic spatial strategy, with farreaching implications for the spatial pattern of regional economic development and regional economic development policies [6].

Space, like other economic factors, also generates economic benefits, and a rational and orderly regional spatial structure will generate positive benefits for economic development, while disorderly spatial development will generate negative benefits, which are not conducive to sustainable regional development. Therefore, the evolution of regional spatial structure is important content and performance of regional economic development and one of the driving forces of the evolution of the regional economic system [7]. The study of the spatial structure of the central urban agglomeration and its evolution law is of great theoretical significance for the scientific recognition of the evolution of the economic spatial structure of the urban agglomeration in the northeast region, which is a "problem area" with natural, economic, social, and policy uniqueness. 
The study of the spatial pattern of the regional economy and its evolution law is an important part of the analysis of regional economic growth process, growth differences, and regional economic growth dynamics. The paper's research on the spatial structure evolution of economic growth rate and efficiency as well as the quality of urban agglomerations and its coupling law is of some significance to enrich the theoretical study of economic growth of urban agglomerations. Uneven growth of the regional economy and coordinated regional development remain the main trends in the evolution of regional spatial structure. The macropath of regional economic development can only be chosen in the process of unbalanced spatial development, with the strengthening of the overall economic strength and the regulation of regional development policies to achieve the concentration of regional economic production and the convergence of living standards.

\section{Current Status of Research}

Industrial location is a complex organism that is influenced by a variety of factors such as labor, capital, and equipment, and there are some linkages between these influences, some of which can interact with each other, making industrial location construction far more difficult than other location construction. For example, an inadequate supply of labor can cause labor costs to increase, while an excess supply of labor can cause labor costs to decrease [8]. Industrial location construction needs to adopt different strategies according to the characteristics of the location. If industrial production is in an area with a relatively backward economy and low labor cost, labor can be used for processing and production to save the expenditure on purchasing equipment; if industrial production is in an area with relatively high labor cost and developed technology, consideration should be given to introducing advanced equipment and using equipment for production to save labor cost. In short, the construction of zones must be carried out according to the actual situation of each region to adopt a targeted program to give full play to the advantages of the region and improve economic efficiency [9]. The use of a behavioral matrix to study locational theory emphasizes the role of incomplete information and nonoptimal behavior on locational choice. The behavioral matrix consists of an information horizontal axis and an information utilization capability axis, and individual decision-makers are located on this behavioral matrix [10]. The information level axis represents the quality and quantity of information that each decision-maker has when making a certain locational decision; the information utilization capability axis represents the various capabilities of the decision-maker to use information.

In general, the behavioral theory emphasizes the role of information and divides the factors affecting location construction into internal and external factors. Internal factors include corporate expansion and mergers, the decision making ability of the actors and subjective preferences, etc.; external factors include geography, climate, market conditions, and labor supply and cost, etc. The transition probability (conditional probability) of urban ecological efficiency is not all concentrated on the main diagonal but deviated to a certain extent. The transition probability of urban ecological efficiency is relatively concentrated on the main diagonal, and the degree of deviation is slightly smaller. In summary, the change trend of urban ecological efficiency in the research sample period is relatively stable. At present, the research on behavioral school theory mainly stays in the analysis of external factors and tends to study the connection between behavior and individuals from the perspective of space, believing that biological factors, management system, technology level, and capital, and other elements will have restrictions and influence on the behavior space. The core of the gradient development theory is to respect the disparity that exists in the economic and industrial development of each region, to use the life cycle theory of industry to divide the industrial development of each region accordingly, to introduce and sort out the gradient in which the industrial development of each region is located, to analyze the advantages and disadvantages of the industrial development of different regions on this basis, and to determine the corresponding industrial construction and development programs, so that the advantages of each region can be given full play, and the further development of the industry will be promoted [11].

Specifically, regions on the lower gradient tend to be more backward in economic development and more suitable for the development of labor-intensive industries and primary industries and can transfer mature industries to the lower gradient; regions on the higher gradient are generally more economically developed and rich in technological resources and capital and are more suitable for the development of technology and capital-intensive industries, which are conducive to the development of mature and budding industries. The development of technology and capital-intensive industries is more suitable for growth and budding industries. As the research on gradient development theory continues to deepen, some scholars propose that the gradient development theory should be dynamic, because the economic development level of each region is not static, and it is necessary to adjust and optimize the industrial development plan according to the economic development of each region and the social resource consumption situation. However, when the industrial development of economically developed regions reaches a certain level, they will fall into a bottleneck of industrial development and produce a diffusion effect, at which time the economies of scale will gradually decrease and their production factors and labor force will be transferred to the backward regions, which can stimulate the development of the backward regions to a certain extent and have a very important positive effect on the development of the backward regions. Therefore, the dual economic structure has both positive and negative effects on the economic development of the backward regions, and to promote the economic development of the backward regions and narrow the gap, it is necessary to regulate these two effects [12]. 


\section{Data Envelopment Analysis Model (DEA) Analysis of the Spatial Structure of Regional Enterprises and Its Impact on Regional Economic Development}

3.1. Data Envelopment Analysis Model Construction. Data Envelopment Analysis (DEA) is an evaluation of the relative effectiveness of multiple input and output elements, which we call Decision Making Units (DMUs), through the idea of mathematical planning. It is further explained that by projecting these DMUs onto the "frontier" of the production possibility set, we can see whether these DMUs are located on the "frontier" to determine whether the best results are achieved and to understand the difference between the DEA derived from these DMUs and the best efficiency. The size of the $\beta$ coefficient also implies the speed of urban eco-efficiency convergence (the smaller the coefficient, the faster the convergence). This shows that, compared with the central and western cities, non-resource-based cities, key cities, and cities in non-two-control areas, the eco-efficiency of eastern cities, resource-based cities, non-key cities, and cities in the two control areas has a faster convergence rate. The difference between the DEA and the optimal efficiency of these DMUs can be understood. It is worth emphasizing that the DEA model is used to evaluate the relative effectiveness between the input and output DMUs, so it is necessary to choose the appropriate amount of input and output indicators; otherwise, it will affect the accuracy of the efficiency value.

$$
h_{i}=\frac{v^{t} x_{i}}{u^{t} y_{i}}=\frac{\sum_{r=1}^{n} y_{n j}}{\sum_{i=1}^{m} x_{i f}} .
$$

When using DEA algorithms to analyze specific problems, the following three factors are most used for analysis: overall efficiency, scale efficiency, and technical efficiency [13]. The overall efficiency indicates the maximum output that can be obtained with the most advanced technology and is usually solved concerning a certain scale of reward model; the scale efficiency indicates whether the decision unit is the most appropriate under the conditions of the current production scale and can be expressed as the quotient of the overall efficiency and the technical efficiency; the technical efficiency indicates the minimum input cost when the output is as large as possible and is based on a variable proportional compensation model for solving. By applying the commonly used VTS safety evaluation index system, $n$ decision units DMUs to be evaluated are established, with a total of $m$ input indicators and $s$ output indicators. Eventually, the required evaluation index of any one decision unit:

$$
\min h_{j}=\frac{\sum_{r=1}^{t} y_{r} u_{t 0}}{\sum_{i=1}^{m} x_{i} v_{j 0}} .
$$

In the DEA model evaluation system, when the efficiency evaluation index of the nth decision unit indicator is satisfied equal to 1 , this decision unit is defined as effective. And when this index is less than 1 , this decision unit is defined as invalid. In the process of implementing efficiency analysis based on the
DEA model, multiple decision units are jointly valid; i.e., their efficiency values are 1 at the same time; at this time, it is impossible to complete the simultaneous comparison of these valid samples. Taking the built-up areas and main residents' gathering points of various districts and counties as the key development units further improves public service facilities such as education, medical care, and infrastructure such as transportation, post, and telecommunications and focuses on the integrated development of urban and rural primary, secondary, and tertiary industries, based on the natural geography and social economy of mountainous areas, development conditions, and appropriate and reasonable layout of public service infrastructure and gradually narrows the gap in the basic conditions of economic and social development in the mountainous area of the central Yunnan city group. Therefore, the super-efficiency model is applied in the paper to analyze such problems [14]. In the process of evaluating the efficiency of decision units based on the CCR model, first, the efficiency frontier surface is established and includes the decision of this unit, and if this decision unit lies on the frontier surface, then this decision unit is valid. Conversely, this decision unit is noneffective. Similarly, the frontier surface is constructed based on the units that lie outside the decision unit based on the set generated by the super-efficiency model. And in the actual construction of the super-efficiency model, the units that form the frontier surface are not the invalid decision units generated by the CCR model. Therefore, the effective decision units cannot be exactly improved by the super-efficiency model, but there is no further effect on the ineffective decision units.

$$
Z_{i j}^{\prime}=0.3 \cdot\left(\frac{a_{i j}+b_{j}}{Z_{i j}+b_{j}}\right)+0.7 \cdot\left(\frac{a_{i j}-b_{j}}{Z_{i j}+b_{j}}\right) .
$$

In this paper, in testing the validity of the path of action in which economic interactions affect spatial spillover of eco-efficiency and hence eco-efficiency changes, the joint system of equations seemingly uncorrelated regression (SUR) method was used for estimation, as fixed effects were more convincing than random effects. When single equation estimation was performed for each model separately, the same hair found that the Hausman test always significantly rejected the original hypothesis that random effects were more appropriate. Accordingly, the fixed effects model is accepted in this paper when performing joint estimation.

$$
\left\{u^{T} y_{i}+s . \beta^{T} x_{i} \leq 0, \quad i=1,2, \ldots, n, \beta \geq 0, u \leq 0\right.
$$

It is an analysis method to measure the spatial direction distribution characteristics of geographical elements, which can accurately characterize the spatial concentration area and the dispersion degree and diffusion direction of the spatial distribution of geographical elements and is now widely used in spatial pattern analysis [15]. The standard deviation ellipse mainly includes four basic parameters: center of gravity, rotation angle, and long-axis and short-axis standard deviation; the center of gravity indicates the change of the center of gravity of economic efficiency in spatial distribution, the rotation angle reflects the trend and direction of the spatial 
distribution of geographical elements, and the standard deviations of long-axis and short-axis indicate the dispersion degree of geographical elements in the major and minor directions, respectively.

$$
\begin{aligned}
& \delta_{x}=\frac{\sqrt{3 \lim _{m \longrightarrow \infty} \sum_{i=1}^{m}\left(x_{i} \sin \theta+y_{i} \cos \theta\right)^{2}}}{m}, \\
& \delta_{y}=\frac{\sqrt{2 \lim _{m \longrightarrow \infty} \sum_{i=1}^{m}\left(y_{i} \cos \theta-x_{i} \sin \theta\right)^{2}}}{m} .
\end{aligned}
$$

To summarize the research done by various scholars using different methods, among the existing financing efficiency evaluation methods, principal component analysis is more of a qualitative analysis of financing efficiency under the influence of various factors at the theoretical level and is usually used in combination with other methods to make up for the lack of quantitative analysis; the fuzzy comprehensive evaluation method is based on affiliation analysis and has certain quantitative research advantages compared with principal component analysis. Similarly, the hierarchical analysis method applies less quantitative data and relies too much on qualitative indicators with insufficient persuasiveness to conclude, and because it is impossible to easily determine the respective weights for a large number of statistical indicators in the case of a large number of indicators, the shortcomings of the effectiveness and applicability of the method are obvious. In contrast, the indicator system of the DEA model can link the process of precapture and postallocation of corporate funds, and the evaluation of financing efficiency by this method can consider the whole operation process of corporate financing comprehensively, as shown in Figure 1.

The introduction of the theory of evolutionary economic geography and the intersection of multidisciplinary methods is a useful exploration of the localization of tourism research and the diversification of tourism research methods. The efficiency of economic growth mainly reflects the status of input and output, which is reflected by the growth of total factor productivity and marginal quantity, determines the cost and sustainability of economic growth, and is mainly achieved through technological innovation. The quality of economic growth mainly reflects the pros and cons of the level of economic development, mainly through structural optimization and sharing of results, including the optimization of industrial structure, regional structure, urban and rural structure, and the improvement of people's consumption level and welfare level. Evolutionary economic geography mainly studies the evolutionary process of economic units in space, and its theoretical basis includes generalized Darwinism, complexity theory, and path dependence theory, etc. It pays more attention to the evolution of complex systems and emphasizes the past-time evolutionary process and spatial heterogeneity. Due to the complexity and heterogeneity of the regional tourism industry system, evolutionary economic geography can therefore better explain the spatial-temporal evolution process and driving mechanism of regional tourism industry efficiency, and the empirical results can provide a more scientific policy basis for the development of regional tourism industry.

$$
\begin{aligned}
T & =T_{B}-T_{v}, \\
T_{P} & =\lim _{m_{p}} \longrightarrow \infty \sum_{t=1}^{m_{p}} \frac{\sqrt{e_{i} e_{p}+1 n e_{p}}}{2\left(m_{p}+1\right)} .
\end{aligned}
$$

The source of regional tourism industry efficiency differences gradually shifts to interregional differences; that is, the tourism industry efficiency differences within the subcity group tend to narrow, and the differences between the three major subcity groups are expanding trend. This is due to the weaker tourism resource circulation barriers within the subcity groups, more uniformity in the allocation of tourism industry resources, and better regulation and guidance of tourism industry movement development, while the interregional differences are gradually highlighted and expanded by the differentiation phenomenon under the rapid development of tourism industry. The intraregional differences are calculated by weighting the differences within the subcity groups so that the contribution rate of subcity group differences to the total differences can be inferred. Comparing the contribution rates of the three, the contribution rate of intracity-ring differences to the total differences remains above $40 \%$, and the contribution rate of the differences at the end of the cyclical fluctuations is the same as the contribution rate of the differences in the base period. The contribution rate of the intracity cluster of Changhua and Poyang Lake is more significant, from $28.87 \%$ to $15.25 \%$ in the base period to $3.27 \%$ and $4.24 \%$ in the end period, respectively (Figure 2).

For the full sample estimates, the economic competition has a significant dampening effect on the increase in eco-efficiency, with, on average, a $0.08 \%$ decrease in eco-efficiency for every $1 \%$ increase in economic competition. Notable control variables are the level of economic development, population density, industrial structure, and wage level. The increase in economic development, population density, and wage level significantly improves urban eco-efficiency; in particular the increase in population density on eco-efficiency reaches 2.26 . Industrial structure has a significant negative effect on ecoefficiency; on average, for every $1 \%$ increase in industrial structure, eco-efficiency decreases by $0.29 \%$. This indicates that in the current context of the new normal and high-quality development of the preeconomic economy, improving the level of regional economic development still helps to improve ecoefficiency. In the initial stage of the development of regional tourism industry, the accessibility of transportation guarantees the accessibility of tourist destinations, enables tourism resources to exert their use value and value, directly affects tourism output, and is the initial driving force of the temporal and spatial evolution of regional tourism industry efficiency. Moderate population density is conducive to improving the intensive use of production factors such as land, which in turn improves resource use efficiency and has a significant positive impact on the improvement of eco-efficiency. The increase in wage level implies an increase in urban labor productivity, which contributes to the improvement of urban eco-efficiency. In addition, the share of secondary industry, mainly heavy industry, has a significant negative impact on the improvement of eco-efficiency, indicating that the overall improvement of 


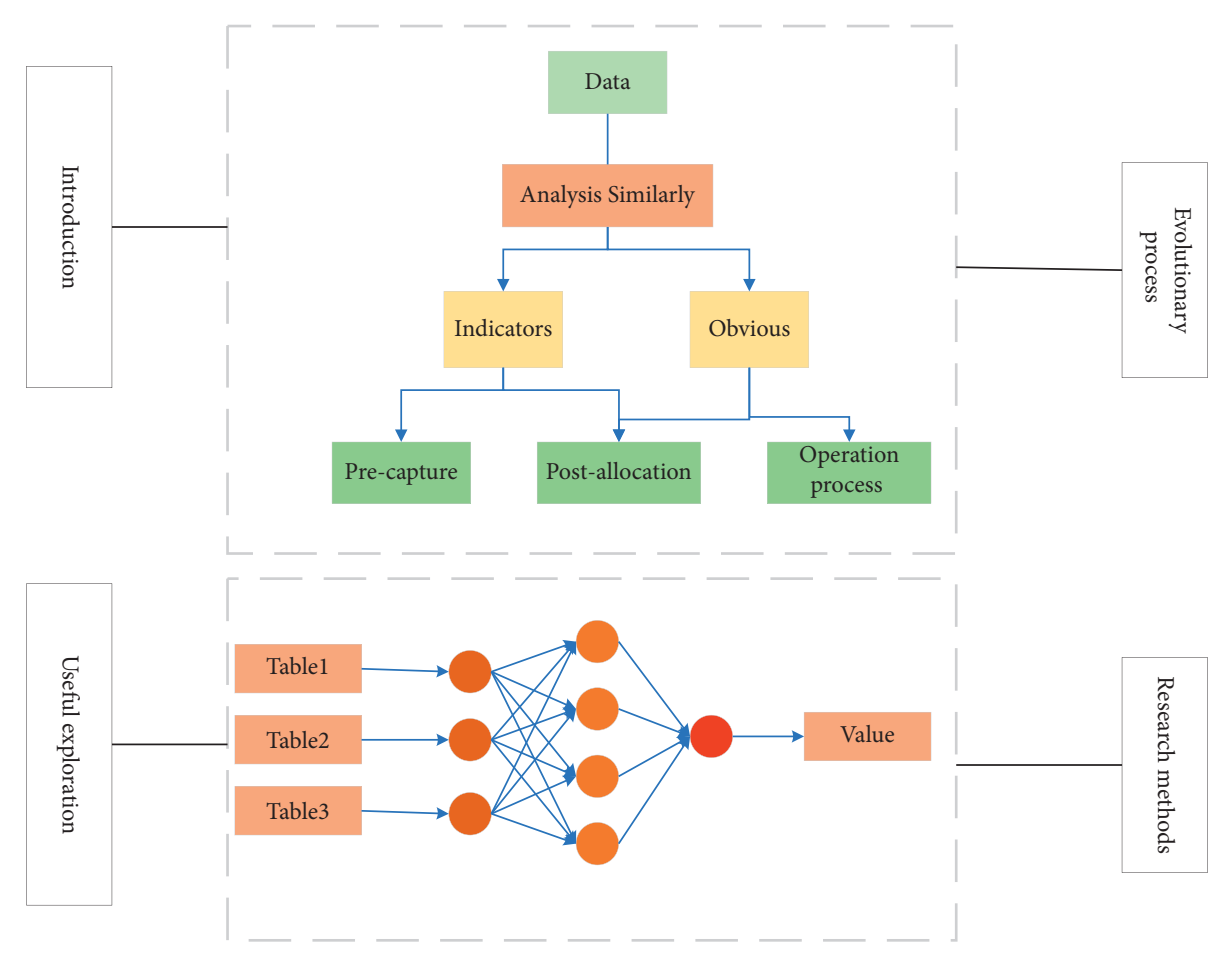

Figure 1: Data envelopment analysis model.

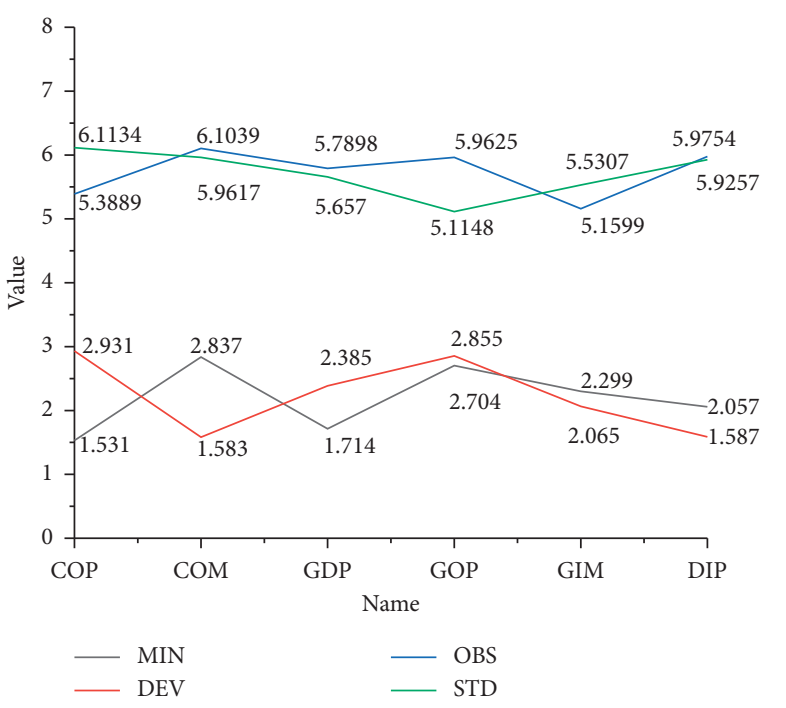

FIgURE 2: Descriptive statistics of variables related to economic interactions.

urban eco-efficiency can be achieved through the transformation and upgrading of industrial structure and the effect of increasing the share of tertiary industry by reducing the share of secondary industry or increasing the level of advanced industrial structure. The above study found significant heterogeneity in urban characteristics and heterogeneity in city size.

\subsection{Spatial Structure of Regional Enterprises and Their Impact} on Regional Economic Development Design. The spatial organization of urban agglomerations refers to the spatial distribution and association of towns and cities within urban agglomerations and the morphological characteristics of their combinations. The spatial organization structure includes the type of monopole nucleus center system structure and the type of polycentric town system structure. The spatial distribution of town systems in urban agglomerations has a random fractal structure within a certain range. There are three basic methods for describing the spatial structure of urban agglomerations: one is the aggregation fractal dimension, which mainly describes the characteristics of the system elements gathered around the core; the second is the spatial association fractal dimension, which describes the relative distribution of the elements of the town system from the density of multiple points; the third is the network fractal dimension, which directly describes the characteristics of the system spatial structure from the distribution of spatial elements. In this paper, the spatial association fractal dimension is chosen to simulate the fractal characteristics of the town system structure of the central Jilin urban agglomeration and analyze the interaction and spatial association between towns in the urban agglomeration, and its basic model and calculation process are as follows:

$$
\begin{aligned}
& C(r)=\lim _{n \longrightarrow \infty} \frac{2}{n^{3}} \sum_{i, j=1}^{n} H\left(r-N_{i j}\right), \\
& H\left(N+d_{i j}\right)= \begin{cases}1, & d_{i j}<N, \\
0, & d_{i j}=N, \\
-1, & d_{i j}<N .\end{cases}
\end{aligned}
$$

The spatial structure of towns in urban clusters includes not only the hierarchical scale structure and spatial organization structure, but also the functional structure of towns, 
and the functional structure of towns is the change of division of labor and functions undertaken by towns as spatial connection points in urban clusters, and the functional structure is an important part of the spatial structure of urban clusters, and only the coordination and complementarity of structure and function can make urban clusters realize the unity of spatial structure and functional structure and urban clusters. Only then can a spatial pattern with reasonable layout, complete system, and perfect function be formed, as shown in Figure 3.

The introduction of driving mechanism analysis in the study of spatial spillover of eco-efficiency can not only enrich the research content of eco-efficiency-related disciplines, but also reveal the law of spatial interaction of regional ecoefficiency and provide new ideas and a new basis for enhancing eco-efficiency [16]. However, when the industrial development of an economically developed area reaches a certain level, it will fall into a bottleneck period of industrial development and produce a diffusion effect. At this time, the economies of scale will gradually decrease, and its production factors and labor will also be transferred to backward areas. The upward stimulus for the development of underdeveloped areas has a very important and positive effect on the development of underdeveloped areas. Therefore, the dual economic structure has both positive and negative effects on the economic development of underdeveloped areas. To promote the economic development of underdeveloped areas and narrow the gap, these two effects must be adjusted. This paper addresses the urgent issue of the spatial spillover driving mechanism of eco-efficiency and proposes to build a theoretical and empirical analysis framework from four aspects: economic interaction, transportation development, regional innovation, and environmental regulation, to comprehensively and systematically study the spatial spillover driving mechanism of regional eco-efficiency using methods such as mathematical model derivation and econometric model testing and to empirically test the effects of various driving factors on the spatial spillover of eco-efficiency from the city level using large sample data. The spatial spillover mechanism of regional eco-efficiency is studied comprehensively and systematically.

$$
\begin{aligned}
E_{i k} & =\frac{Y_{i k}^{*}}{X_{k}^{t} u_{i k}^{*}}, \\
D & =\frac{V^{r}}{V_{0}}=D_{z_{1}} D_{z_{2}} \ldots D_{z_{n}} D_{r s d} .
\end{aligned}
$$

In this paper, a nonconvex common frontier superefficiency DEA model is used to measure eco-efficiency, aiming to fully consider factors such as heterogeneous technologies and to achieve a comprehensive identification of cities. After measuring eco-efficiency, this paper observes the spatial and temporal evolution and regional differences of urban eco-efficiency from a dynamic perspective [17]. This paper uses DEA-GIS, spatial correlation analysis, and spatial econometric models to reveal the spatial and temporal evolution of eco-efficiency and the spatial spillover driving mechanism of different regions and types of cities, which reflects the integrated innovation of the method.

In the process of regional economic development, the effects of "spatial dependence" and "spatial spillover" have an inescapable influence on economic development. Due to the existence of the first law of geography, the regional economy has extensive spatial correlation characteristics. In the process of regional economic analysis, due to the existence of spatial dependence, part of the variation of the dependent variable is interpreted as the correlation between each observation and the neighboring observations, which is not in line with the assumption of mutual independence of samples in most classical economics and econometric analysis. The evolutionary characteristics and laws of economic phenomena cannot be fully revealed. Therefore, in the analysis and processing of spatial data, appropriate spatial statistical analysis methods need to be used, as shown in Figure 4.

Geostatistics is a science that studies natural phenomena that are both stochastic and structural, or spatially correlated and dependent, based on regionalized variables and with the help of variation functions. It is used to study the spatial correlation and spatial dependence of regional economic statistics, as well as the laws of variation and evolution of spatial patterns. The main difference between geostatistics and classical statistics is that geostatistics considers both the size and statistical distribution characteristics of the sample values and the spatial location of the samples as well as the spatial distance and analyzes the statistical characteristics of the data as well as the spatial characteristics through the spatial distance weighting values. For the analysis of regional economic spatial correlation characteristics, there is mainly spatial autocorrelation characteristics analysis and hot spot area evolution characteristics analysis.

Regional economic polarization and the expansion of regional economic development differences are inevitable processes in the process of regional economic development; regional economic differences are one of the important features of the regional economic development situation, and the existence and evolution of regional economic differences have a positive and negative impact on the coordinated development of the regional economy. On the one hand, the existence of regional economic differences is the basis for a regional division of labor and regional competition, and moderate regional differences are conducive to the formation of regional economic development dynamics and competitiveness, promote the flow and optimal allocation of regional factors of production, and promote competition among regions; on the other hand, excessive regional economic differences will aggravate local market segmentation, and the long-term existence or excessive regional differences will encourage the prevalence of local protectionism and hinder regional division of labor and collaboration and impede regional economic development. It hinders regional division of labor and collaboration and weakens the economic development capacity of less developed regions, thus affecting the sustainable development of the region's overall economy. 


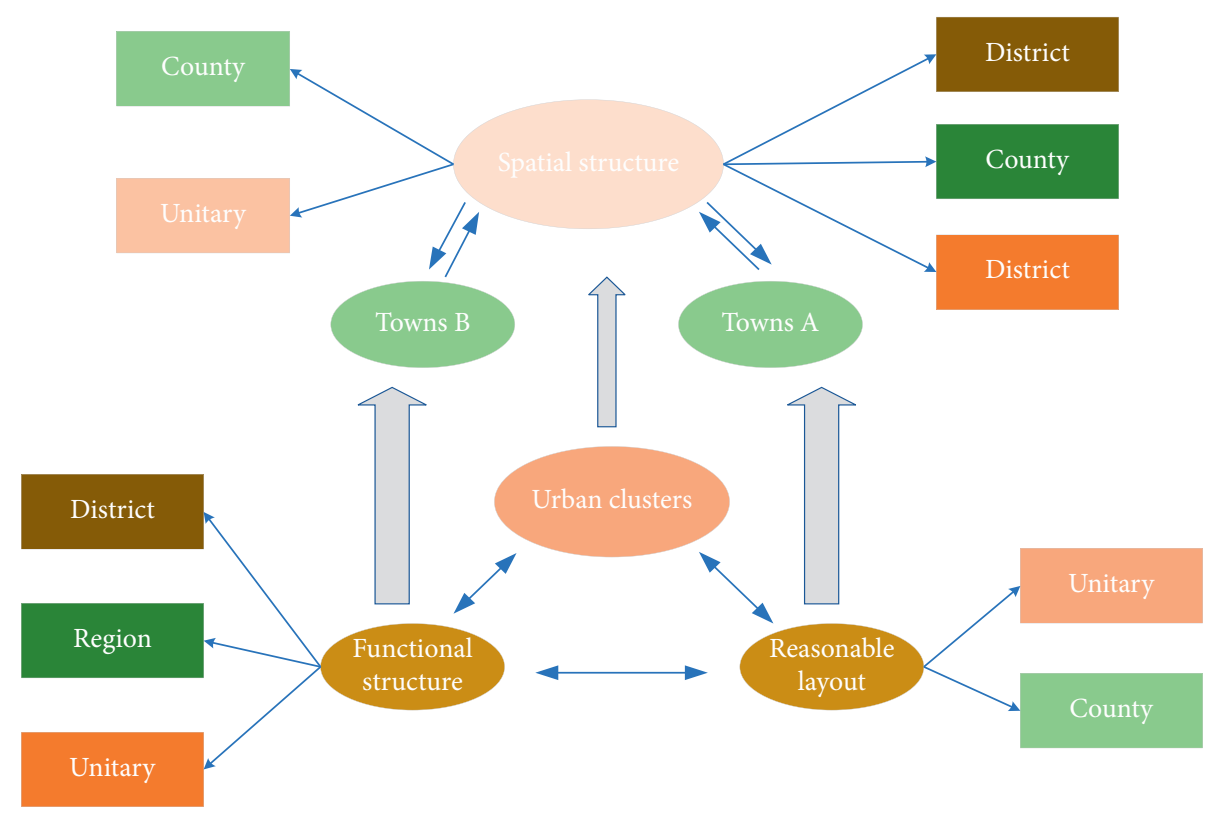

FIgURE 3: Spatial structure and regional economic development framework.

\section{Analysis of Results}

4.1. Data Envelopment Analysis Model Results. If the transfer probability (conditional probability) is concentrated on the main diagonal, it implies that the change in eco-efficiency of the city is small, and the more the transfer probability (conditional probability) deviates from the main diagonal, the greater the change in eco-efficiency of the city is. The 3D spatial distribution map can show the distribution height of the probability density well, but it is more difficult to analyze the distribution of the transfer probability (conditional probability) density relative to the main diagonal, so the $3 \mathrm{D}$ spatial distribution map is transformed into a $2 \mathrm{D}$ contour map by projection, which can capture the contour of the transfer probability (conditional probability) distribution density deviating from the main diagonal. The transfer probabilities (conditional probabilities) of urban eco-efficiency are not all concentrated on the main diagonal but are deviated by a certain degree. The transfer probability of urban eco-efficiency is relatively concentrated on the main diagonal and deviates to a slightly lesser extent. In summary, the trend in urban eco-efficiency is relatively stable over the study sample period, as shown in Figure 5.

First, the results of estimation without considering spatial factors are analyzed. To fully account for regional heterogeneity and to fully examine the convergence of various types of urban eco-efficiency, full sample and group regressions were conducted using dynamic GMM models after grouping the study sample, focusing on the results of the two-step approach given that the results estimated by the two types of methods are very similar. Overall, the estimated coefficients of the time-lagged term of urban eco-efficiency are significantly greater than 0 and less than 1 at the $1 \%$ level, indicating that there is significant $\beta$ convergence of urban eco-efficiency with significant global $\beta$ convergence and club $\beta$ convergence characteristics. For the full sample, the convergence of eco-efficiency becomes faster when control variables are considered (the estimated coefficient

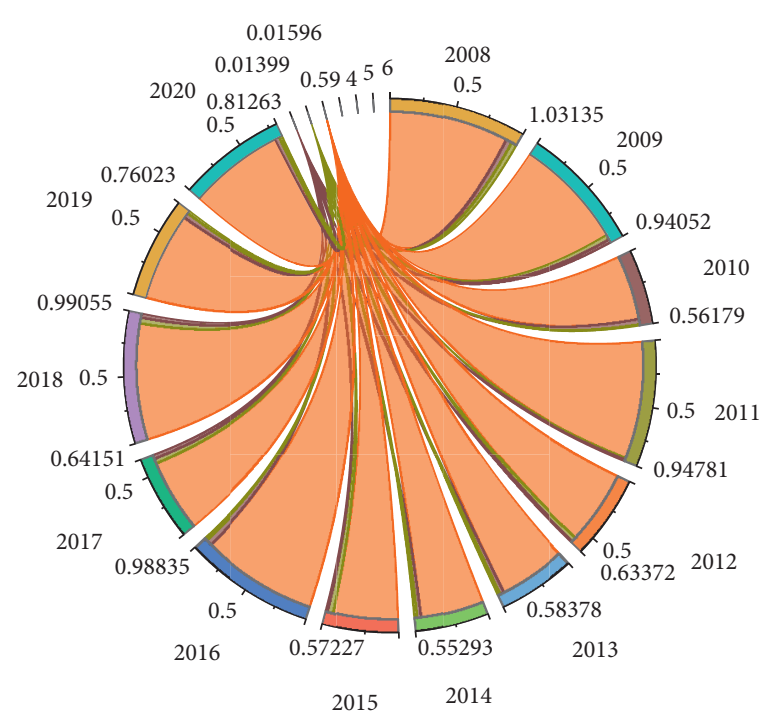

FIgURE 4: Trends in industry efficiency variability.

of the lagged term of eco-efficiency on values is smaller), initially indicating that the rate of convergence of eco-efficiency is overestimated if the factors influencing eco-efficiency are not controlled; i.e., the conditional $\beta$ convergence is faster compared to absolute $\beta$ convergence. Thus, key influences on ecoefficiency are included in the subsample regressions. The magnitude of the $\beta$ coefficient also implicitly indicates how quickly urban eco-efficiency converges (the smaller the coefficient the faster the convergence), thus indicating that eastern cities, resource-based cities, nonfocused cities, and cities in non-two-control zones have faster convergence rates compared to central and western cities, non-resource-based cities, key cities, and cities in non-two-control zones. In the context of the current preeconomy entering a new normal and high-quality development, improving the level of regional economic 


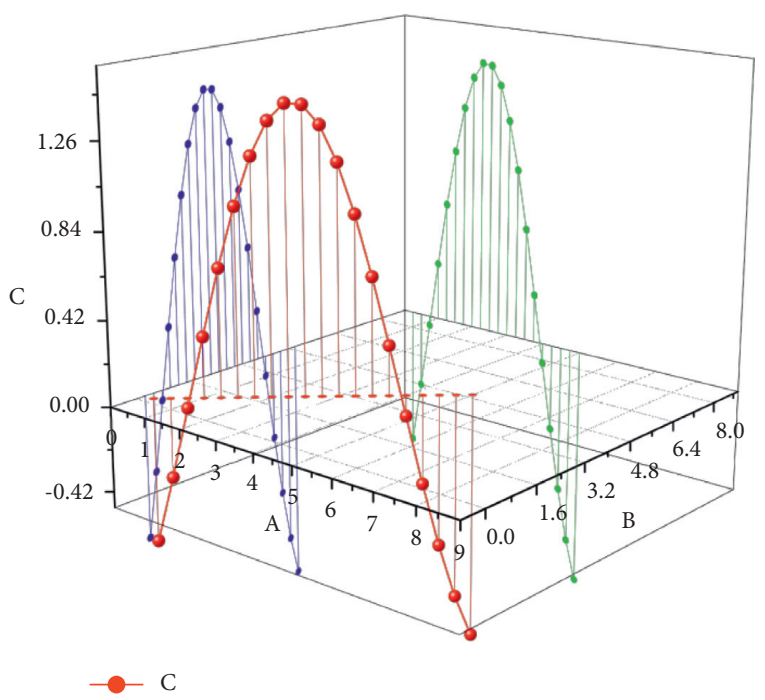

Figure 5: Model measurement results.

development is still conducive to improving ecological efficiency. A moderate population density is conducive to improving the intensive use of land and other production factors, thereby improving resource utilization efficiency, and has a significant positive impact on the improvement of ecological efficiency. The empirical findings imply that resource-based cities with lower eco-efficiency have a higher rate of convergence, implying that the eco-efficiency of such cities can achieve catch-up with the eco-efficiency of other cities. However, the relatively backward central and western cities and key cities of environmental protection are locked in a lower state of eco-efficiency due to factors such as lower economic development level and serious ecological pollution and cannot achieve catch-up. It is also shown that the national policy of establishing cities in two control zones is indeed conducive to the improvement and convergence of eco-efficiency. It is further found that population density, which reflects economic agglomeration, has a positive effect on the improvement of urban eco-efficiency. Increasing the regional wage level is beneficial to the improvement of urban eco-efficiency, but the industrial structure has a significant negative effect on the improvement of urban eco-efficiency. Therefore, the focus should be on optimizing urban industrial structure through industrial structure upgrading and industrial restructuring to improve urban eco-efficiency comprehensively, as shown in Figure 6.

The continuous strengthening of the depth and breadth of intercity economic cooperation accelerates the flow of factors and market transactions, realizes resource sharing, and acts on eco-efficiency enhancement through factor allocation effects, market scale effects, and resource utilization efficiency, which in turn affects the spatial spillover of ecoefficiency in neighboring cities. The rapid flow of production factors contributes to the spatial allocation and optimal reorganization of resources between regions. On the one hand, economic cooperation enhances the speed and scope of the flow of production factors between cities, accelerates the development and utilization of economic resources, and realizes the optimal allocation of production factors in a

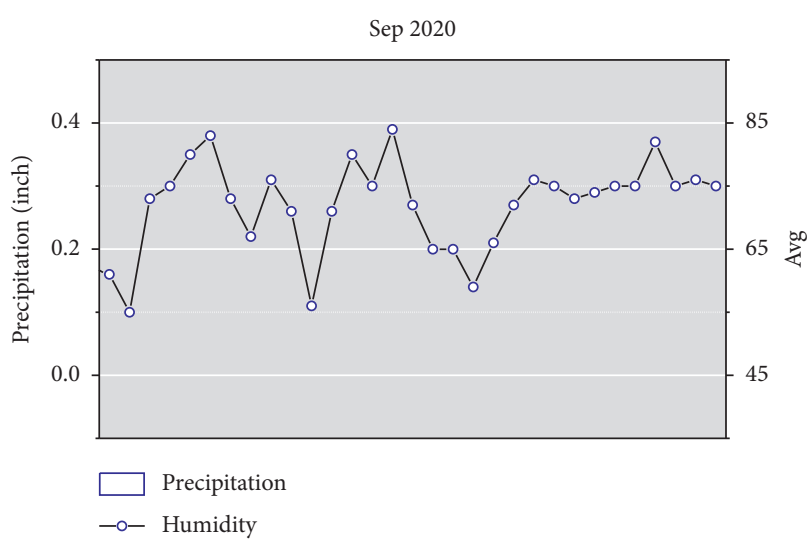

FIgURE 6: Efficiency results.

larger geographical area. On the other hand, economic cooperation promotes the frequent flow of human capital (carriers of knowledge and information) between cities, accompanied by the diffusion, exchange, and interaction of knowledge, information, and science and technology, thus stimulating production and improving the efficiency of economic operations [18]. Thus, economic cooperation can influence the spatial spillover of eco-efficiency in neighboring cities at least through the intercity factor allocation effect, market scale effect, and resource use efficiency pathways, which in turn affect eco-efficiency enhancement.

4.2. Development Impact Results. Most of the developmentoriented districts and counties with comprehensive economic efficiency and total factor productivity in the Central Yunnan Urban Agglomeration are in the marginal areas of the Central Yunnan Urban Agglomeration, and the biggest obstacles to its development are incomplete infrastructure and unreasonable allocation of production resources, etc. Meanwhile, like a highland urban agglomeration, the topography of the Central Yunnan Urban Agglomeration is mainly based on highland mountains and intermountain basins, and the unique topographic conditions and historical development reasons make the districts and counties in the urban agglomeration differ greatly in terms of the natural environment and the unique topographic conditions and historical development make the districts and counties in the urban agglomeration have big differences in a natural environment and social development, so it is necessary to promote the development of urban-rural integration in the Central Yunnan Urban Agglomeration. The urban built-up areas and major residential gathering points of each district and county as the key development units further improve public service facilities such as education, medical care, and other infrastructures such as transportation, post, and telecommunications, focus on the integrated development of urban and rural industries, and lay out public service infrastructure appropriately and reasonably according to the natural geography and socioeconomic development conditions of mountainous areas, to gradually reduce the basic conditions of economic and social development among the mountainous dam areas of the Central Yunnan Urban Agglomeration. Gap It is also 
innovating the development model of small- and mediumsized towns and characteristic towns, focusing on creating demonstration areas for the integration of industries and cities, such as the Dian Zhong New District, and taking a new path of integration of industries and cities and interactive development of urban and rural areas.

This requires that attention be paid to the important role of science and technology innovation in the economic and social development of the Central Yunnan Urban Cluster, adhering to innovation-driven development and enhancing the capacity for science and technology innovation. To increase the investment in science and technology-related aspects, the government issues relevant policy documents to play a guiding role, establishes special funds for science and technology projects, provides subsidies and corresponding rewards for enterprises' major science and technology innovation activities, drives financial institutions and civil society funds to invest more in science and technology innovation enterprises and fields, and at the same time actively encourages and guides enterprises to increase their investment in independent innovation and develops and cultivates business incubators, crowdsourcing spaces, and other innovations. At the same time, we actively encourage and guide enterprises to increase their investment in independent innovation, develop and nurture enterprise incubators, crowdsourcing spaces, and other innovative bodies, and carry out technological innovation activities, as shown in Table 1.

The improvement of the quantity of economic growth is a prerequisite for the improvement of the quality of economic growth, but the quantity of economic growth is different from the quality of economic growth. The main pursuit of economic growth quantity growth or economic growth quality improvement of a development strategy choice is also a choice of value orientation. The quantity of economic growth solves the problem of growth rate, which is mainly realized by the accumulation of economic development factors and can be visually reflected by the GDP growth rate. The efficiency of economic growth mainly reflects the input-output situation, which is reflected through the growth of total factor productivity and marginal quantity, and determines the cost and sustainability of economic growth, which is mainly realized through technological innovation [19]. The introduction of driving mechanism analysis in the study of ecological efficiency spatial spillover can not only enrich the research content of ecological efficiency-related disciplines, but also reveal the spatial interaction law of regional ecological efficiency and provide new ideas and new basis for improving ecological efficiency. The quality of economic growth mainly reflects the level of economic development, mainly through the optimization of the structure and the sharing of results, including the optimization of industrial structure, regional structure, and urban and rural structure and the improvement of people's consumption level and welfare level, as shown in Figure 7.

The coefficients of total factor productivity have a wide range of variation and very significant spatial divergence, indicating that, for different enterprise agglomeration areas,
TABLE 1: DEA super-efficiency measurements.

\begin{tabular}{llllll}
\hline Name & CRS & ERS & SES & PTE & TES \\
\hline Ping county & 0.92 & 0.45 & 0.72 & 0.83 & 0.75 \\
You county & 0.58 & 0.95 & 0.85 & 0.42 & 0.45 \\
Bai county & 0.58 & 0.85 & 0.50 & 0.85 & 0.65 \\
Water county & 0.78 & 0.45 & 0.55 & 0.65 & 0.52 \\
Heng county & 0.62 & 0.85 & 0.75 & 0.45 & 0.45 \\
\hline
\end{tabular}

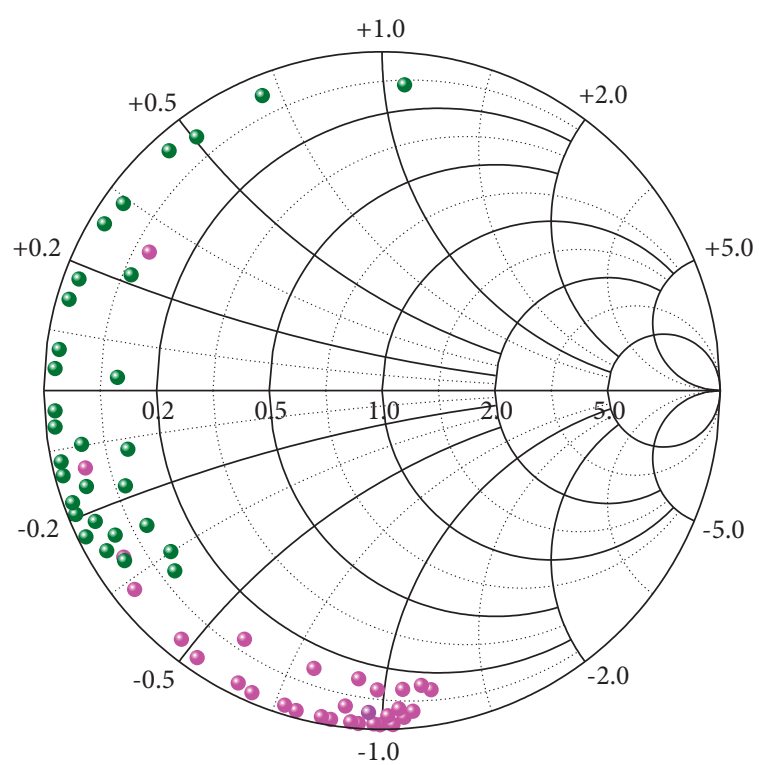

FIGURE 7: Results of the measurement of the drivers of the evolutionary impact of industrial efficiency.

the impact of total factor productivity varies greatly. In the core area of Xi'an Xianyang and its peripheral areas, the smaller the total factor productivity DEA-M index is, the faster the number of enterprises grows. Based on market competition theory, productivity leads to higher average costs, thus reducing the market competitiveness of enterprises, which should discourage further derivation, entry, and aggregation of enterprises in the region. But there are also firm exit replacement costs to consider here, which may offset this effect to some extent. The self-reinforcing circular cumulative development of these firms clustered in the core area based on path dependence is highly inertial and over time makes for path locking and some degree of growth. Further, firms in the core may choose to enter for other reasons, and thus the impact of total factor productivity is offset by the effects of other factors. For example, the core area's easy access to external exports and low transportation costs enhances the market competitiveness of firms around $\mathrm{Xi}$ 'an, and the more convenient living conditions and social environment relative to other regions in Shaanxi Province also incentivize firms to derive and enter.

The improvement of regional transportation accessibility can largely promote the flow of tourism flow factors between regions, reduce the spatial and temporal lag in the allocation of tourism industry factors, and thus enhance the efficiency of the regional tourism industry. In the initial stage of regional tourism industry development, transportation 
accessibility ensures the accessibility of tourism sites, enables tourism resources to play their use and value, directly affects tourism output, and is the initial driving force for the spatial and temporal evolution of the regional tourism industry efficiency [20].

\section{Conclusion}

From the spatial dimension, the overall spatial pattern of economic efficiency in the Central Yunnan Urban Agglomeration evolved relatively steadily during the study period, the center of gravity coordinates has been located within the main urban area of Kunming, the spatial pattern of the oval of the standard deviation of county economic efficiency is generally spreading in the direction, and economic efficiency shows significant positive spatial correlation [21]. The spatial variation of economic efficiency counties is complex, the degree of local spatial agglomeration has weakened, only a few districts and counties have reached the optimal level of comprehensive economic efficiency, and the number of districts and counties with optimal pure technical efficiency is high, but the districts and counties with pure technical efficiency not in the optimal state are mostly at the level of low or no pure technical efficiency, which has become the main reason for restricting the improvement of economic efficiency in the Central Yunnan Urban Agglomeration, and the scale efficiency of most districts and counties is at the medium. Most of the districts and counties are in the stage of increasing scale payoff and need to moderately increase the amount of input of production factors and resources. County differences in total factor productivity are obvious, and changes in technological progress have the greatest impact on total factor productivity changes in the Central Yunnan Urban Agglomeration, followed by changes in pure technical efficiency. During the study period, the change in total factor productivity of each industrial segment in Shaanxi Province was modeled as the dependent variable and the change in location quotient as the independent variable. The fitting results verify that there is a positive correlation between the change in total factor productivity of a two-digit industry and the change in its location quotient; i.e., an increase in specialization leads to a corresponding increase in its total factor productivity. The location quotient of the industry with the strongest regional technological linkage is also introduced into the model, and the results show that increased specialization in other industries with technological linkages in the region causes an acceleration in the growth of total factor productivity in that industry.

\section{Data Availability}

The data used to support the findings of this study are available from the corresponding author upon request.

\section{Conflicts of Interest}

The authors declare that they have no conflicts of interest.

\section{Acknowledgments}

This work was supported by the Key Project of Chinese Ministry of Education of the 14th Five-Year Plan of the National Education Sciences Planning (DIA210365), "Study on the Interactive Relationship between Spatial Structure of Local Enterprise and Supply of Talent in Local Colleges from the Perspective of Urban Transformation."

\section{References}

[1] P. Andersen and N. C. Petersen, "A procedure for ranking efficient units in data envelopment analysis," Management Science, vol. 39, no. 10, pp. 1261-1264, 1993.

[2] A. Charnes, W. W. Cooper, and E. Rhodes, "Evaluating program and managerial efficiency: an application of data envelopment analysis to program follow through," Management Science, vol. 27, no. 6, pp. 668-697, 1981.

[3] R. D. Banker, A. Charnes, and W. W. Cooper, "Some models for estimating technical and scale inefficiencies in data envelopment analysis," Management Science, vol. 30, no. 9, pp. 1078-1092, 1984.

[4] R. D. Banker and R. Natarajan, "Evaluating contextual variables affecting productivity using data envelopment analysis," Operations Research, vol. 56, no. 1, pp. 48-58, 2008.

[5] K. Chen and J. Guan, "Measuring the efficiency of China's regional innovation systems: application of network data envelopment analysis (DEA)," Regional Studies, vol. 46, no. 3, pp. 355-377, 2012.

[6] V. Charles and L. F. Zegarra, "Measuring regional competitiveness through data envelopment analysis: a Peruvian case," Expert Systems with Applications, vol. 41, no. 11, pp. 53715381, 2014.

[7] R. D. Banker, "Maximum likelihood, consistency and data envelopment analysis: a statistical foundation," Management Science, vol. 39, no. 10, pp. 1265-1273, 1993.

[8] M. Dinc and K. E. Haynes, "Sources of regional inefficiency," The Annals of Regional Science, vol. 33, no. 4, pp. 469-489, 1999.

[9] Y. Zhou, Y. Kong, and T. Zhang, "The spatial and temporal evolution of provincial eco-efficiency in China based on SBM modified three-stage data envelopment analysis," Environmental Science and Pollution Research, vol. 27, no. 8, pp. 8557-8569, 2020.

[10] M. Song, J. Tao, and S. Wang, "FDI, technology spillovers and green innovation in China: analysis based on data envelopment analysis," Annals of Operations Research, vol. 228, no. 1, pp. 47-64, 2015.

[11] L. M. Seiford, "Data envelopment analysis: the evolution of the state of the art (1978-1995)," Journal of Productivity Analysis, vol. 7, no. 2, pp. 99-137, 1996.

[12] S.-C. Xu, Y.-F. Zhou, C. Feng, Y. Wang, and Y.-F. Li, "What factors influence PM2.5 emissions in China? An analysis of regional differences using a combined method of data envelopment analysis and logarithmic mean Divisia index," Environmental Science and Pollution Research, vol. 27, no. 27, pp. 34234-34249, 2020.

[13] K. Cullinane, T.-F. Wang, D.-W. Song, and P. Ji, "The technical efficiency of container ports: comparing data envelopment analysis and stochastic Frontier analysis," Transportation Research Part A: Policy and Practice, vol. 40, no. 4, pp. 354-374, 2006.

[14] C. Stolp, "Strengths and weaknesses of data envelopment analysis: an urban and regional perspective," Computers, 
Environment and Urban Systems, vol. 14, no. 2, pp. 103-116, 1990.

[15] A. D. Athanassopoulos, "Assessing the comparative spatial disadvantage (CSD) of regions in the European Union using non-radial data envelopment analysis methods," European Journal of Operational Research, vol. 94, no. 3, pp. 439-452, 1996.

[16] D. Ferraz, E. B. Mariano, D. Rebelatto, and D. Hartmann, "Linking human development and the financial responsibility of regions: combined index proposals using methods from data envelopment analysis," Social Indicators Research, vol. 150, no. 2, pp. 439-478, 2020

[17] P. Murias, F. Martinez, and C. De Miguel, "An economic wellbeing index for the Spanish provinces: a data envelopment analysis approach," Social Indicators Research, vol. 77, no. 3, pp. 395-417, 2006.

[18] J. $\mathrm{Li}$ and $\mathrm{Y} . \mathrm{Xu}$, "Evaluating restrictive measures containing housing prices in China: a data envelopment analysis approach," Urban Studies, vol. 53, no. 12, pp. 2654-2669, 2016.

[19] R. Lado-Sestayo and Á. S. Fernández-Castro, "The impact of tourist destination on hotel efficiency: a data envelopment analysis approach," European Journal of Operational Research, vol. 272, no. 2, pp. 674-686, 2019.

[20] C. A. P. Barros and C. A. Santos, "The measurement of efficiency in Portuguese hotels using data envelopment analysis," Journal of Hospitality \& Tourism Research, vol. 30, no. 3, pp. 378-400, 2006.

[21] J. $\mathrm{Xu}, \mathrm{B}$. Li, and $\mathrm{D}$. $\mathrm{Wu}$, "Rough data envelopment analysis and its application to supply chain performance evaluation," International Journal of Production Economics, vol. 122, no. 2, pp. 628-638, 2009. 